\begin{tabular}{ccc}
\hline & International Journal of Engineering \& Technology, $7(2.12)(2018) 151-155$ \\
SPC & Website: www.sciencepubco.com/index.php/IJET \\
Research Paper & Jechnology \\
\hline
\end{tabular}

\title{
Selection of damping coefficient of simplified mount module to control transmissibility of environmental response under nobase mass-block
}

\author{
Gee-Soo Lee ${ }^{1}$, Moo-Yeon Lee ${ }^{2}$, Ki-Hyun Kim ${ }^{3}$, Chan-Jung Kim ${ }^{4 *}$ \\ ${ }^{1}$ School of Automotive and Mechanical Design Engineering, Youngsan University, 288 Junam-ro, Yangsan-si, \\ Kyungnam-do, 50510, Republic of Korea \\ ${ }^{2}$ Department of Mechanical Engineering, Dong-A University, Hadan 840, Saha-gu, Busan, 49315, Republic of Korea \\ ${ }^{3}$ Division of Mechanical Convergence Engineering, Silla University, 140 Baegyang-daero, 700beon-gil, \\ Sasang-gu, Busan, 46958, Republic of Korea \\ ${ }^{4}$ Department of Mechanical Engineering, Pukyong National University, 365 Sinseon-ro, Nam-gu, Busan, 48547, Republic of Korea \\ *Corresponding author E-mail: cjkim@pknu.ac.kr
}

\begin{abstract}
Background/Objectives: This paper focused on the simplified design of passive mount modulein electric power plants using only spring and damper elements.

Methods/Statistical analysis: The selection of elements in a proposed simplified passive mount module was proceeded under the requirement, which is to show the response level same or less as compare to the case of current mount module. The response at the upper location of mount affect to negative effect on the responsible electric power plants so the design criterion should be satisfied with the newly proposed simple mount module.

Findings: The frequency response function between the force and response acceleration at upper position of mount module was calculated from the theoretical mount module and the transmissibility function, between two response accelerations at two different passive mount modules, was evaluated for interesting harmonic frequencies (from $1 \mathrm{X}$ to $4 \mathrm{X}$ ). The primary interesting frequency $(\mathrm{X})$ was determined at $30(\mathrm{~Hz})$ since the operation condition of the combustion engine in electric power plant is scheduled to be operated at constant $1,800(\mathrm{rev} / \mathrm{min}$ ) Several simulation cases can be obtained for different combination of selected dampingcoefficients at the proposed mount module. The magnitude of transmissibility function should be less than one all interesting frequencies and the reasonable condition of the simple mount module can be derived from the simulation result.Then, the validation of the designed simplified mount module was conducted by preparing two kinds of mount module and the acceleration responses were measured at 1,800(rev/min) operation under 100\% electric load. The spectral response at interesting frequencies confirms the superiority of the newly proposed mount module.

Improvements/Applications: The simplified structure of mount module can be possible to save installation cost and time simultaneously and it is easy to conduct the maintenance of mount module.
\end{abstract}

Keywords: Simplified Mount Module; Transmissibility Function; Acceleration Response; Emergency Electric Power Plant; Model of Mount Module

\section{Introduction}

Mechanical systems consists ofmany sub-components and connecting elements so that global behavior of the concerned system can be analyzed reliably if and only if the relationship between subcomponents is identified clearly and formulations of the connecting elements are defined reasonably. So the general mechanical system should be understood from a microscopic range, such as each small component or connecting one, to more globalized viewpoints, such as system-level understood of multi-body system. One of most difficulties in modeling process of the multi-body system is the identification of the property of connecting elements since most of subcomponents shows non-linear behavior during operation and linearization of the connecting parts are applied for the compact modeling of complicated structures. Passive mount module is used to connect two independent component in order to eliminate any influence from one part to other part with respect to force or excitation and several sub-components are frequently used such as spring, damper or other mechanical devices.

The mount module is designed to control the natural frequency of the supporting main system or to play an isolator of the source excitation from one system to another one. So the mount module was widely used in the mechanical systems and many techniques were developed so far. The type of mount module can be categorized into three parts, passive mount, active and semi-active according to the freedom of the controllability of the nature of mount coefficients. The active type mount module was studied by many researchers for the application of the control theory to enhance the quality of response at the interesting locations [1-4]. Semi-active type mount module was developed in many engineering industry owing to its superior ability over passive one and the cost of adaptation was cheaper than the active one [5-8]. The passive type mount module was still mostly used in many applications due to its cheap installation cost as well as simple structure of the concerned module. In addition, many innovative mechanical elements are used in the modeling of the passive type mount module [9-12] and some non- 
linear elements are studied nowadays to enhance its performance of isolation under compact design philosophy [13-15]. An emergency electric power plant is one of application of passive mount module to isolate the excitation triggered from a combustion engine as well as protect the power plant itself from the reaction response at the mount locations.

The emergency electric power plant was mandatory to install at the basement floor of the building in South Korea to supply required electric energy in case of unexpected blackout accident or other special events. The energy source was prepared by an internal combustion engine so that considerable excitations are sourced during the operation of the power plant and the excitation is normally proportional to the electric load of the power generation. To keep the response at the basement floor as soon as possible, several passive mount modules are attached at the lower frame of the power plant The passive mount module of an emergency electric power plant are generally installed with passive type one and it is consisted of several mechanical elements, such as spring, damper and base mass-block, and the modeling of the responsible mount module is therefore somewhat complex as compared to other simple mount module. The practical problem regarding the mount module is related with a base mass-block because the heavy mass-block should be shielded with damping materials or supported with several spring elements to isolate the mass-block from neighboring system. The mount module with a base mass-block is complicated structure to install it and the effort of maintenance is also hardto achieve it. However, the base mass-block is very effective component to keep the critical frequency of the supporting system at low frequency range so that it is not easy to find countermeasures in case of eliminating it. That is the main reason in this study to focus on the design of the simplified mount module of the emergency electric power plant only using one spring element and one damper one.

In this study, the linearized modeling of the passive mount module of the electric power plant was conducted using mechanical elements, mass, spring and damper, including a power plant as well as a base mass-block. The current mount module was modeled with complicated structure as compared to the proposed mount module without base mass-block. It is assumed that the external force was assigned at plant location and the response was also calculated at the same location to evaluate the reaction response at the electric power plant with respect to the self-excitation. The characteristics of mechanical elements, spring and damper, was measured using separate measurement facility and the frequency response function between the force and response was derived under Laplace transform in frequency domain. In case of the proposed mount, several cases of damping coefficients are applied for the simulation to find the reasonable combination of the mount case under the fixed coefficient of spring because the choice of spring element has some limitations due to the heavy static loadsto support the main power plant. Then, the theoretical transmissibility between two responses, both for current mount and the proposed one, was calculated to find the best case of the proposed mount module against the current mount case. The criterion of the transmissibility is less than value one in all interesting frequency points. The simulation results were also verified experimentally by preparing the two mount module for the same power plant with $750 \mathrm{KW}$ capacity. The operation of the internal combustion engine in a power plant was done under $1,800(\mathrm{rev} / \mathrm{min})$ and the response at the upper location of mount module was measured with $100 \%$ electric loads of power plant. The interesting frequency of the response was determined at four main harmonic ones, from $1 \mathrm{X}$ to $4 \mathrm{X}$, under $\mathrm{X}(=30 \mathrm{~Hz})$ was defined as rotating velocity of combustion engine. Both cases of responses, for current mount and the proposed one, were compared to confirm the superiority of the proposed mount module at the aspect of the reaction response at the power plant location.

\section{Modeling of mount module}

\subsection{Emergency electric power plant and passive mount module}

The emergency electric power plant plays key role to supply for necessary electric energies for the concerned building or other facilities when main electric source is suddenly blocked by accident. The emergency electric source can be generated by internal combustion engine installed at the power plant and considerable vibrations should be accompanied during operation. If the vibrations are allowed to the environmental structures without any anti-vibration solution, the exposed structures may encounter with the vibrationfatigue problems. One of countermeasures are attached with mount module to cut the vibration path from the source from a combustion engine to environments and passive-type mount module has been widely used in power plant industry since the passive-type mount is easy to install as well as to supply with cheap price. The passive mount module is consisted of several mechanical elements, such as spring, damper, and additional heavy mass-block can incorporated with mount module to control the excitation from power plant. In this paper, two kinds of passive-type mount modules are prepared to evaluate the performance of vibration isolation; one is the current mount module with base mass-block and the other is proposed simple mount module. The target emergency electric power plant with $7,500 \mathrm{KW}$ capacity and passive-type mount modules are illustrated in Fig. 1 and Fig. 2, respectively.

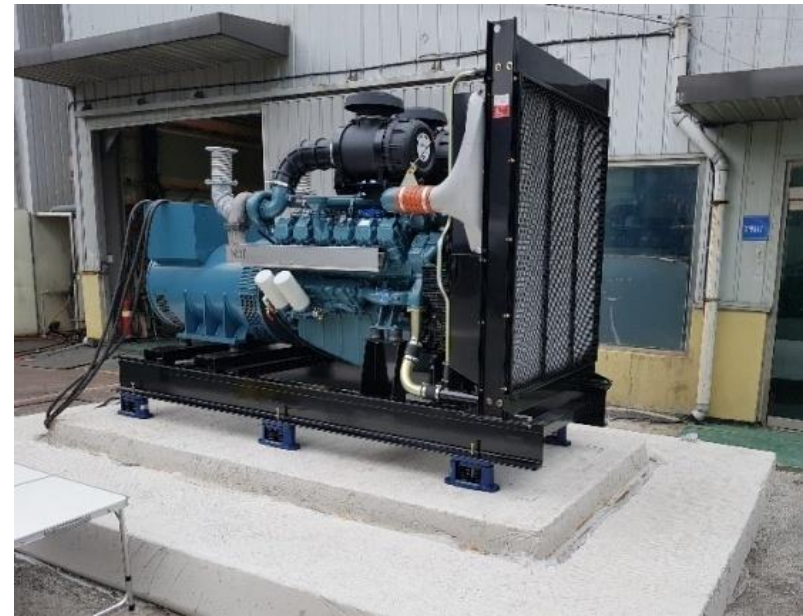

Fig. 1: Emergency Electric Power Plant with 7, 500KW Capacity.

(A) Current Mount

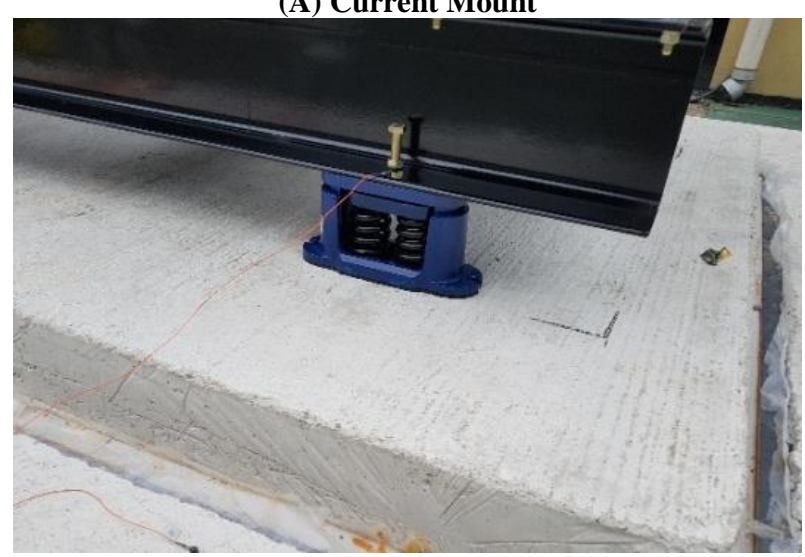


(B) Proposed Mount

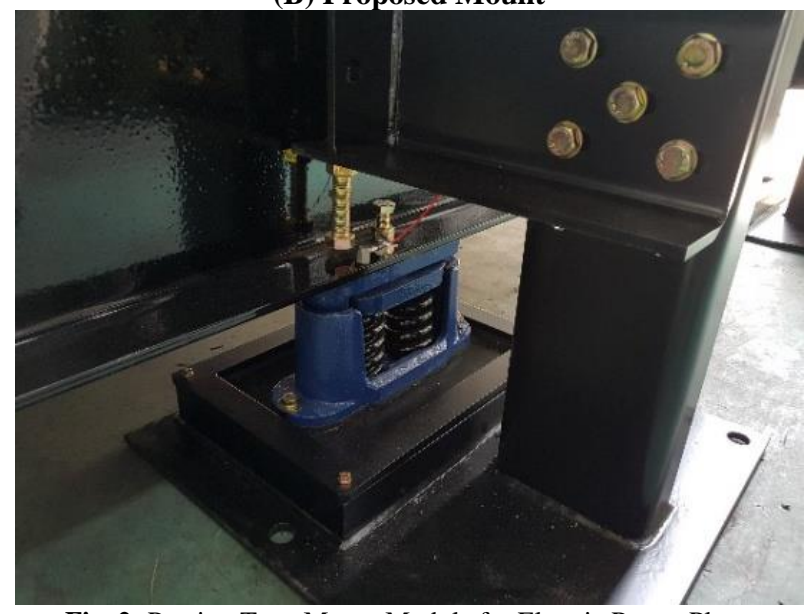

Fig. 2: Passive-Type Mount Module for Electric Power Plant.

The current mount module supported the electric power plant with six spring components and a heavy base mass-block was located at the beneath of the spring components as shown in Fig. 2(a). In addition, the base mass-block was isolated with the environmental floor with damping materials that can be modeled as damper component during modeling of the mount module. So the configuration of the current mount module is complex with several sub-components so that the installation process of the current mount module is rigorous and the manufacturing cost should be increased. Even more, it is not easy to conduct a maintenance service in case of failure of sub-components. On the other hands, the structure of the proposed mount module in Fig. 2(b) was simple with spring components and damping one without consideration of the heavy base mass-block. The manufacturing price can be saved and the installation process is also simple. If some failure of sub-components can found during the inspection of the proposed mount module, the replacement of the failure component can be conducted easily as compared to the current mount module. Due the simple structure of the proposed mount, additional stopper structure was attached at the mount module to account for the unexpected earthquake. The design of the stopper was beyond of this study, but it represents the advantage of the proposed simple structure of mount module.

\subsection{Modeling of passive mount module}

The objectives of this study was focused on the feasibility of the simple structure of passive-type mount module to replace the current mount module with a base mass-block. To design a new simple mount, it is necessary to construct a model of mount module for two cases, the current complexed mount module and the simple proposed one. All mechanical elements are assumed to be linear one so that the constructed mount module is also modeled as linear system. The configuration of the linear model of two passive-type mount modules are illustrated in Fig.3. Here, $M_{P}, M_{b}$ and $M_{B}$ are equivalent masses of power plant, base mass-block and building, respectively, and it was assumed to be $M_{B}=10 M_{p}$ since the mass of building is definitely larger than that of power plant. The spring element in current mount module was defined as $K_{p}$ and damping materials were defined using both the spring coefficient $K_{c p}\left(\approx 1,000 K_{p}\right)$ and damping coefficient $C_{p}$. The characteristics of proposed mount module was modeled using spring coefficient $K_{p}$ and damper was modeled as different damping coefficient $C_{p}^{\prime}$, respectively. In addition, the spring coefficient of building is assumed to be $K_{B}\left(=K_{P} / 10\right)$ that makes the building model as rigid body during excitation from a power plant.

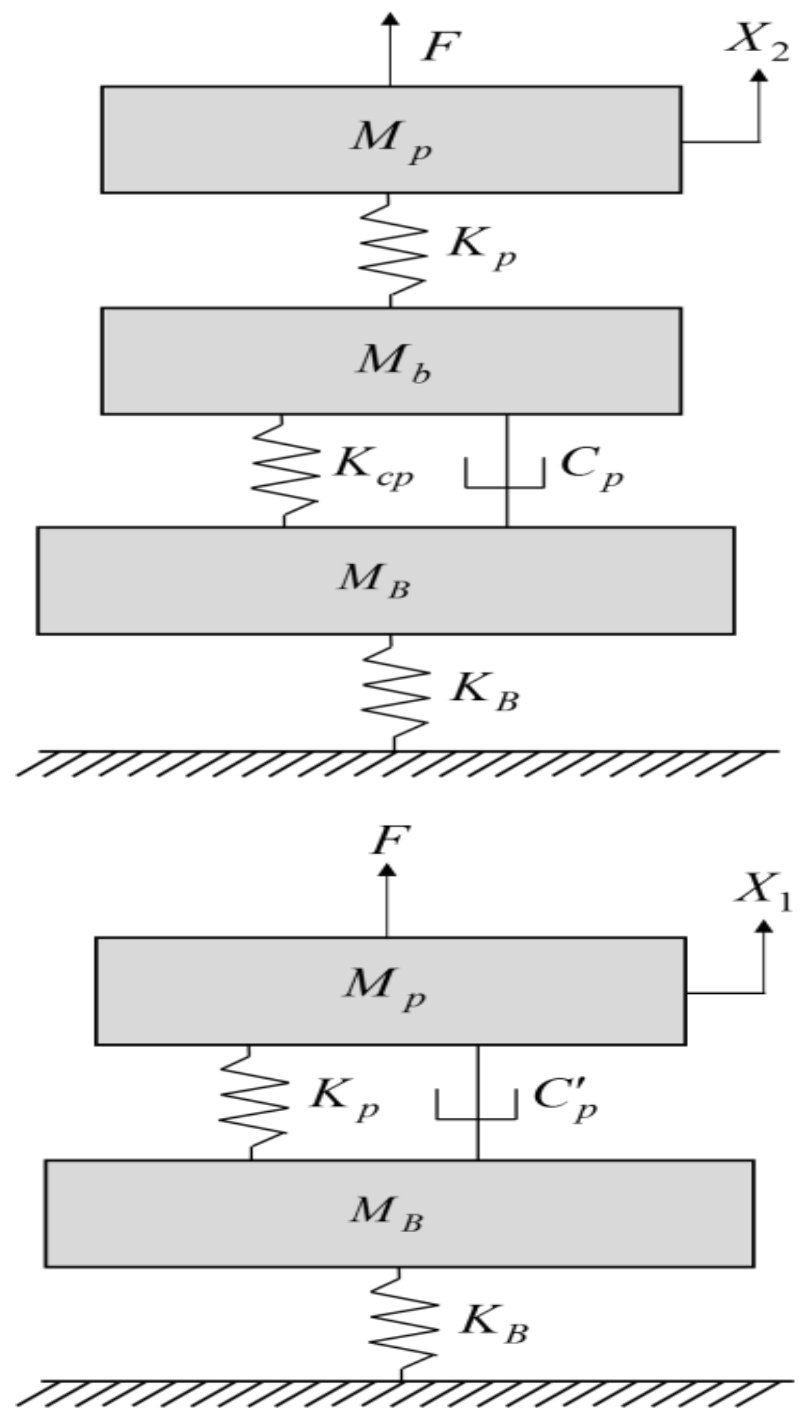

Fig. 3: Configuration of the System Modeling of Passive-Type Mount Module. (A) Current Mount (B) Proposed Mount

The characteristics of both spring component and damper one were identified with hydraulic testing equipment (353.20/MTS) and the test results are summarized in Table 1 . Since the interesting frequency range was determined as from $30(\mathrm{~Hz})$ to $120(\mathrm{~Hz})$, those spectrum is matched with the primary harmonic spectrums of combustion engine at $1,800(\mathrm{rev} / \mathrm{min})$, from $\mathrm{X}$ to $4 \mathrm{X}$.

Table 1: Characteristics of Mechanical Components

\begin{tabular}{lllll}
\hline Com- & Coefficient & & & \\
ponent & $30(\mathrm{~Hz})$ & $60(\mathrm{~Hz})$ & $90(\mathrm{~Hz})$ & $120(\mathrm{~Hz})$ \\
\hline \multirow{2}{*}{ Spring } & $1,050(\mathrm{kN} / \mathrm{m}$ & $1,245(\mathrm{kN} / \mathrm{m}$ & $1,881(\mathrm{kN} / \mathrm{m}$ & $4,399(\mathrm{kN} / \mathrm{m}$ \\
& ) & ) & ) & ) \\
Dampe & $376(\mathrm{Nsec} / \mathrm{m}$ & $216(\mathrm{Nsec} / \mathrm{m}$ & $184(\mathrm{Nsec} / \mathrm{m}$ & $158(\mathrm{Nsec} / \mathrm{m}$ \\
$\mathrm{r}$ & ) & ) & ) & ) \\
\hline
\end{tabular}

The external force, $F$, is assigned at a power plant and the response of both mount cases, current and proposed one, are also assigned at the same location defined as $X_{1}, X_{2}$, respectively. As following the system modeling of passive-type mounted power plant, frequency response functions for each mount cases can be derived in equations (1) and (2), respectively, as Laplace Transform formula.

$$
\frac{X_{1}(s)}{F(s)}=\frac{\left(s^{2} M_{B}+s C_{p}+K_{p}+K_{B}\right)}{\left[\left(s^{2} M_{p}+s C_{p}+K_{p}\right)\left(s^{2} M_{B}+s C_{p}+K_{p}+K_{B}\right)-\left(s C_{p}+K_{p}\right)^{2}\right]}
$$




$$
\frac{X_{2}(s)}{F(s)}=\frac{\left[\left(s^{2} M_{b}+s C_{p}^{\prime}+K_{p}+K_{c p}\right)\left(s^{2} M_{B}+s C_{p}^{\prime}+K_{c p}+K_{B}\right)-\left(s C_{p}^{\prime}+K_{c p}\right)^{2}\right]}{\left[\begin{array}{l}
\left(s^{2} M_{p}+K_{p}\right)\left(s^{2} M_{b}+s C_{p}^{\prime}+K_{p}+K_{c p}\right)\left(s^{2} M_{B}+s C_{p}^{\prime}+K_{c p}+K_{B}\right) \\
-\left(s^{2} M_{p}+K_{p}\right)\left(s C_{p}^{\prime}+K_{c p}\right)^{2}-K_{p}{ }^{2}\left(s^{2} M_{B}+s C_{p}^{\prime}+K_{c p}+K_{B}\right)
\end{array}\right]}
$$

\section{Theoretical approach}

The feasibility of the simple mount module to control the response at the power plant can be evaluated theoretically by the expected responseat the modeling of electric power plant including supporting mount module done in Chapter 2. The frequency response at each mount cases can be formulated under the specification of the target power plant as summarized in Table 2 .

Table 2: Specification of Electric Power Plant

\begin{tabular}{ll}
\hline Item & Detail(dimension) \\
\hline Dimension(L/W/H) & $3390 / 1397 / 2180(\mathrm{~mm})$ \\
Electric capacity & $750(\mathrm{KW})$ \\
Mass of power plant & $6,070(\mathrm{~kg})$ \\
Mass of base mass-block & $6,900(\mathrm{~kg})$ \\
\hline
\end{tabular}

The design criterion of a passive mount module was formulated with the comparison of response at electric power plant, which is upper location of supporting mount module as shown in Fig. 3. In this study, the response index was introduced to compare the isolation capacity of responsible mount module by divide two frequency responses in equation (1) and (2), and the following response index can be calculated as scalar value in frequency domain that is equal to the relative capacity of the proposed mount module with respect to the current mount one as shown in equation (3). Since the response at the power plant should be minimized as soon as possible to protect the target system, the criterion of the response index ( $I_{\text {resp }}$ ) is equal or less than one in all interesting frequency points.

$I_{\text {resp }}(s)=\frac{X_{2}(s)}{F(s)} \frac{F(s)}{X_{1}(s)}=\frac{X_{2}(s)}{X_{1}(s)}$

The expected frequency response functions at the power plant was derived using information in Table 1 and Table 2 for different coefficient of damper element and then, the response index for interesting frequency points (from $\mathrm{X} 1$ to $\mathrm{X} 4$ ) was calculated using equation (3) as summarized in Table 3.

Table 3: Theoretical Response Index for Each Mount Module

\begin{tabular}{lllll}
\hline \multirow{2}{*}{$C_{p}^{\prime}$} & \multicolumn{4}{l}{ RESPONSE INDEX } \\
& $30(\mathrm{~Hz})$ & $60(\mathrm{~Hz})$ & $90(\mathrm{~Hz})$ & $120(\mathrm{HZ})$ \\
\hline 1 (NSEC/M) & 0.65 & 0.95 & 0.95 & 0.95 \\
200(NSEC/M) & 0.65 & 0.95 & 0.95 & 0.95 \\
$1,000(\mathrm{NSEC} / \mathrm{M})$ & 0.65 & 0.95 & 0.95 & 0.95
\end{tabular}

Since the replacement of damper element is easy to conduct it as compared to other mechanical elements including spring one, the simulation was conducted for different damper coefficients. Theexpected response index from the theoretical frequency response functions shows the proposed mount module can achieve smaller response at power plant position than the current one in the interesting frequency points. So the proposed passive mount module has superior capability of response control at upper mount location to protect the electric power plant during operation of combustion engine at $1,800(\mathrm{rev} / \mathrm{min})$. From the simulation, it is also concluded that the damping coefficient $C_{p}^{\prime}$ is not important role in the determination of the response index value. So the current damping materials will be used in the preparation of proposed mount module in experimental verification.

\section{Experimental approach}

The control performance of the simple mount module is still required to verify experimentally by measurement of responses at the upper location of supporting mount module. The accelerometer was attached at the upper location of both mount modules in order to measure acceleration response during operation. The sensor locations are illustrated in Fig. 4 for two mount module cases.

(a) Current Mount (\#1)
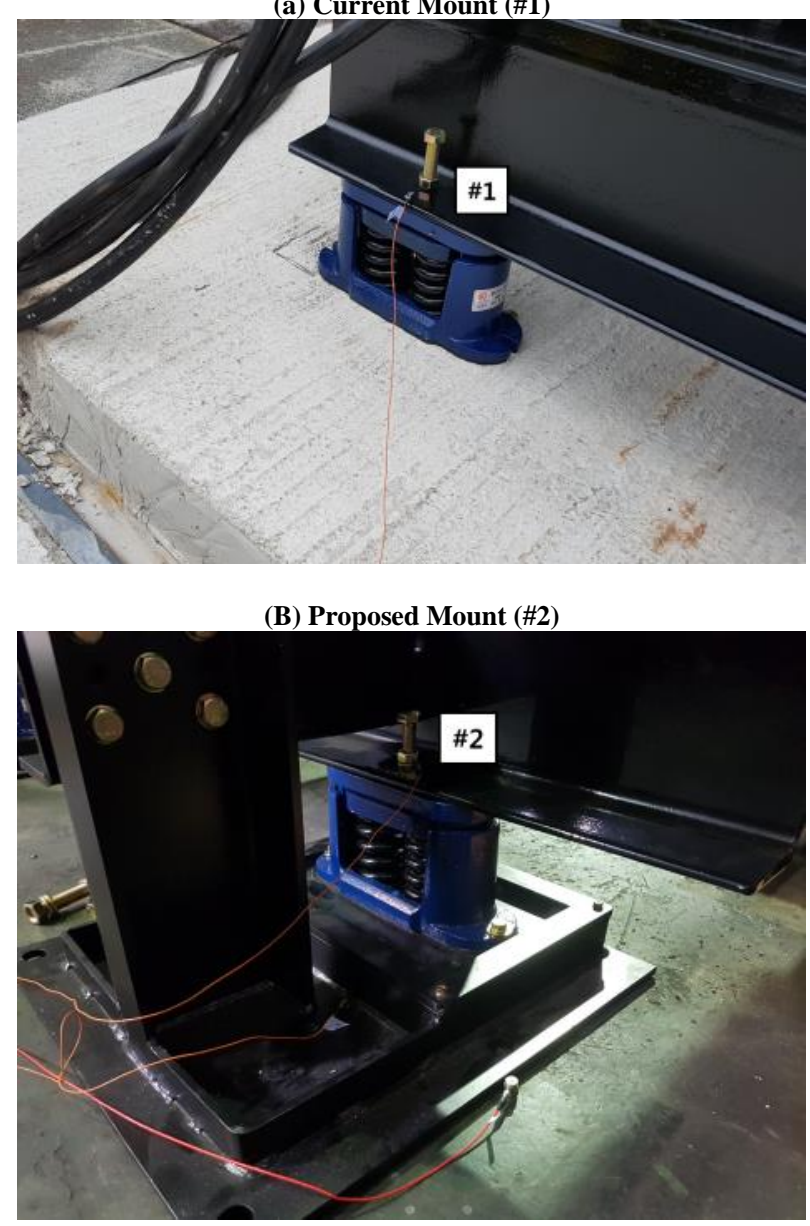

Fig. 4: Configuration of Attached Sensor Locations at Electric Power Plant.

The response at the upper location of mount module was obtained when the electric power plant was operated at normal condition, the rotational velocity of the combustion engine at $1,800(\mathrm{rev} / \mathrm{min})$, under $100 \%$ electric load condition because the excitation from the electric power plant was maximized at those operating condition. The measurement of the response data was obtained with TEST.Lab (Siemens/Germany) and the sampling rate was set for $1,204(\mathrm{~Hz})$ that is more than 10 times of the $4 \mathrm{X}(=120 \mathrm{~Hz})$ harmonic frequency points. The response index was calculated using two measured response accelerations for two cases of mount module, the proposed and the current one. The response index was calculated for the interesting four frequency points and its results were compared with the theoretical ones as shown in Fig.5.

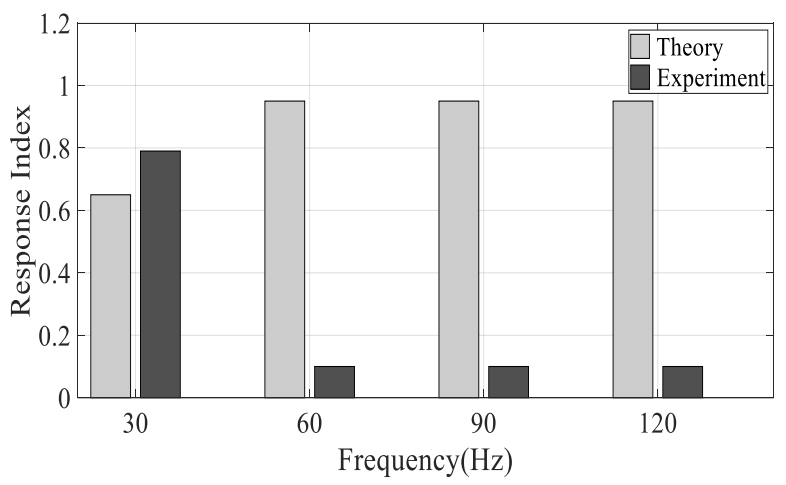

Fig. 5: Comparison of Response Index at the Elect Power Plant Location. 
The calculated response index from the measured response data was also confirmed the proposed mount module was more efficient vibration isolator for all interestingfrequency points even though the structure of the proposed mount module was simply consisted of spring and damper elements without installation of the base massblock. So the proposed mount module is superior to the current mount module for the isolation of the reaction influences from the supporting mount module. The discrepancy between two response indexes was seems to be caused by the damping nature of concrete block in current mount module. The modeling of the current mount module was done only considering the mass of concrete block $M_{b}$ without consideration of energy dissipation at the base mass-block. So the accuracy of the theoretical model will be enhanced by considering the mechanical property of the base mass-block but the few information about the mass-block is available up to now.

\section{Conclusion}

The simplified mount module structure was proposed for an emergency electric power plant without a base mass-block in order to save installation cost and time. The feasibility of the simple structure was verified with system modeling of both mount cases and the frequency response functions are derived from the theoretical models. The response index was introduced to compare response at power plant during operation and it was found that the proposed mount module is superior to the current mount for the suppression of reaction response at plant location from the supporting mount. The response index was also verified experimentally by prepare two mount module for the target $750 \mathrm{KW}$ power plant and the reaction responses were obtained during $100 \%$ electric loads. Both response results, theory and experiment, show the proposed mount module has sound capability to control the reaction response at the electric power plant so that it is reasonable to replace current mount module with the proposed one.

\section{Acknowledgment}

This work was supported by the Open Laboratory Operational Business Developing and Diffusing the Regional Specialization Technology of BISTEP.

\section{References}

[1] Pingzhang Z, Jianbin D, Zhenhua L, Simultaneous topology optimization of supporting structure and loci of isolators in an active vibration isolation system. Computers \& Structures, 2018, 194, pp.74-85.

[2] Beijen M A, Tjepkema D, Dijk J, Two-sensor control in active vibration isolation using hard mounts. Control Engineering Practice, 2014, 26, pp.82-90.

[3] Yang X L, Wu H T, Li Y, Chen B, Dynamic isotropic design and decentralized active control of a six-axis vibration isolator via Stewart platform. Mechanism and Machine Theory, 2017, 117, pp.244252 .

[4] Wang Z, Mak C M, Application of a movable active vibration control system on a floating raft. Journal of Sound and Vibration, 2018, 414, pp.233-244.

[5] Gu X, Yu Y, Li J, Li Y, Semi-active control of magnetorheological elastomer base isolation system utilizing learning-based inverse model. Journal of Sound and Vibration, 2017, 406, pp.346-362.

[6] Santos M B, Coelho H T, Neto F P L, MafhoudJ, Assessment of semi-active friction dampers. Mechanical Systems and Signal Processing, 2017, 94, pp.33-56.

[7] Oh, H U, Choi Y J, Enhancement of pointing performance by semiactive variable damping isolator with strategies for attenuating chattering effects. Sensors and Actuators A: Physical, 2011, 165, pp.385391.

[8] Azadi M, Behzadipour, Faulkner G, Performance analysis of a semiactive mount made by a new variable stiffness spring. Journal of Sound and Vibration, 2011, 330(12), pp.2733-2746.

[9] Kim C J, Kang Y J, Lee B H, Ahn H J, Design sensitivity analysis of a system under intact conditions using measured response data, Journal of Sound and Vibration, 2011, 331(13), pp.3213-3226.
[10] Keulen F, Haftka R T, Kim N H, Review of options for structural design sensitivity analysis. Part 1: Linear systems. Computer methods in applied mechanics and engineering, 2005, 194, pp.3213-3243.

[11] Kim C J, Lee B H, Kang Y J, Ahn H J, Accuracy enhancement of fatigue damage counting using design sensitivity analysis. Journal of Sound and Vibration, 2014, 333(13), pp.2971-2982.

[12] Kim C J, Design sensitivity analysis of a Stockbridge damper to control resonance frequencies. Journal of Mechanical Science and Technology, 2017, 31(9), pp.4145-4150.

[13] Siami A, Karimi H R, Cigada A, Zappa E, Sabbioni E, Parameter optimization of an inertia-based isolator for passive vibration control of Micheangelo'sRondanini Pieta. Mechanical Systems and Signal Processing, 2018, 98, pp.667-683.

[14] Wu Z, Jing X, Sun B, Li F, A 6DOF passive vibration isolator using $\mathrm{X}$-shape supporting structures. Journal of Sound and Vibration, 2016, 380, pp.90-111.

[15] [Lee J, Okwudire C E, Reduction of vibrations of passively-isolated ultra-precision manufacturing machines using mode coupling. Precision Engineering, 2016, 43, pp.164-177. 